\title{
Two Separate Regions in the Genome of the Tobacco Etch Virus Contain Determinants of the Wilting Response of Tabasco Pepper
}

\author{
Meihua Chu, J. J. Lopez-Moya, Cesar Llave-Correas, and T. P. Pirone \\ Department of Plant Pathology, University of Kentucky, Lexington 40546 U.S.A. \\ Received 26 November 1996. Accepted 17 February 1997.
}

\begin{abstract}
Infection of Tabasco pepper by the tobacco etch virus (TEV) typically causes wilting associated with root necrosis. However, a strain of TEV, designated TEV nonwilting (TEV NW), is able to infect Tabasco pepper plants but does not cause wilting. In order to locate the genetic determinants responsible for the wilting response, a full-length cDNA clone of TEV NW from which infectious transcripts can be derived was made. A number of chimeric constructs were prepared by substituting cDNA fragments between TEV HAT (which causes wilting) and TEV NW clones. This approach was used to identify two wilting determinants in TEV HAT: one encompasses the $3^{\prime}$ onethird of the $P 3$ coding region; the other spans the $3^{\prime}$ end of the CI, the 6-kDa protein, and the $5^{\prime}$ end of the VPg-NIa coding regions. Substitution of both these TEV NW fragments into TEV HAT resulted in infection but not wilting of Tabasco pepper, while the replacement of either of the fragments alone did not alter the wilting response. This indicates that both TEV NW regions contain determinants necessary but not sufficient to alter the wilting response and that both must be present in order to avoid the wilting response. There was no difference between the in vitro transcription-translation products derived from constructs containing these regions from TEV HAT and TEV NW.
\end{abstract}

Additional keywords: hypersensitive response.

Tobacco etch virus (TEV) is a member of the genus Potyvirus in the family Potyviridae. Infection of pepper (Capsicum annuum L.) by TEV causes mottling, mosaic, distortion of leaves and fruit, and stunting (Purcifull and Hiebert 1982), while infection of Tabasco pepper ( $C$. frutescens L. cv. Tabasco) results in wilt and subsequent death of the plant caused by root necrosis and disruption of water transport (Ghabrial and Pirone 1967). The root systems of plants that are starting to wilt have a rusty brown, necrotic ring surrounding the vascular tissue (White and Horn 1965). The wilt of Tabasco pepper is considered diagnostic for TEV, and the interaction between them is unique: TEV is the only virus known to induce the wilt in Tabasco pepper, and Tabasco is

Corresponding author: T. P. Pirone; Telephone: 606/257-2682; fax: 606/323-1961; E-mail:ppa133@ukcc.uky.edu

Present address of M. Chu: Department of Plant Pathology and Microbiology, Texas A\&M University, College Station 77843-2132 U.S.A. the only pepper cultivar known to produce this response. Furthermore, the necrosis occurs only in the vascular system of the roots and not in that of the aboveground stems or leaves (White and Horn 1965; Ghabrial and Pirone 1967).

Recently, a strain of TEV that infects Tabasco pepper but does not cause wilt was found in Louisiana and was characterized and designated TEV nonwilting (TEV NW) (Chu et al. 1995). The availability of TEV NW provided an opportunity to characterize the wilting determinants of TEV at the molecular level by comparison with TEV NW. The objectives of this research were to locate and characterize the wilting determinants of TEV.

\section{RESULTS}

Symptoms caused by TEV NW and the viral progeny derived from full-length transcripts of pTEV-NW.

The TEV NW strain used in these studies was selected through three successive single local lesion passages in Chenopodium amaranticolor (Chu et al. 1995). TEV NW caused typical mosaic, etching, and stunting symptoms in tobacco plants, cultivar Kentucky 14, and caused mosaic, mottling, and stunting but not wilting symptoms in Tabasco pepper. The type strain of TEV, TEV HAT (for the sequence, see Allison et al. 1986), which causes wilting of Tabasco pepper, was maintained in our laboratory. An infectious cDNA clone of TEV HAT, pTEV-7DA (a modified version of pTEV-7D) (Dolja et al. 1992) was provided by J. C. Carrington of Texas A\&M University. Plasmid pTEV-7DA will be referred to as pTEVHAT in this study for simplicity.

A full-length cDNA clone of TEV NW (pTEV-NW) was constructed by substituting the complete open reading frame region and portions of the untranslated regions (from $S w a$ I to BstEII, positions 78 to 9,461) into pTEV-HAT and replacing the $B g$ III site located after the poly(A) tail with an SmaI site in order to allow linearization (Fig. 1A). The progeny of pTEVNW infected Tabasco pepper but did not cause wilting, reproducing the phenotype of TEV NW.

The comparative ability of TEV NW and TEV HAT to infect and replicate in the cells of Tabasco pepper roots was determined by quantal infectivity assay (Brakke 1970) of root extracts on tobacco and by immunofluorescent labeling of viral antigens in root cells (Wang et al. 1994). The infectivity assay showed that the concentration of TEV NW was at least 100-fold greater than that of TEV HAT; immunofluorescent 
labeling was present in cells of all types in TEV NW-infected roots, whereas in TEV HAT-infected roots, labeling was restricted to the vascular tissue (data not shown). The necrosis of phloem tissue caused by TEV HAT evidently prevents spread of the virus to other root tissues, which accounts for the higher titer of TEV NW in root extracts.

\section{Localization of a wilting determinant and evidence for the existence of a second determinant.}

A strategy for exchanging fragments between pTEV-NW and pTEV-HAT was adopted in order to identify the wilting determinant. Because of differences in the restriction maps, reciprocal exchange of fragments between the two full-length clones was often not possible, and consequently most of the chimeras were constructed by substitution of genomic regions of pTEV-NW into pTEV-HAT. The series of these full-length chimeric plasmids was designated $\mathrm{pHN}$; the ones with substitution of TEV HAT sequences into TEV NW context were named $\mathrm{pNH}$, with the substituted region indicated by abbreviation of the corresponding flanking restriction sites (Fig. 1B). An asterisk indicates that an SmaI site was exchanged for the original $B g l$ II site used for linearization.
Initially, we focused on the coat protein (CP) coding region, since the CPs of tobacco mosaic virus (TMV) and potato virus $\mathrm{X}(\mathrm{PVX})$ are associated with necrotic responses (Knorr and Dawson 1988; Culver et al. 1991; Santa Cruz and Baulcombe 1993), and on the P1 coding region, which has the highest percentage of amino acid differences between TEV NW and TEV HAT (Chu et al. 1995).

Figure 2 shows the structures of pTEV-HAT, pTEV-NW, and some of the chimeras used to identify a wilting determinant. The TEV NW CP region was substituted into pTEVHAT to create $\mathrm{pHN}[\mathrm{N}-\mathrm{Bs}]$, and the TEV NW P1 region was substituted into pTEV-HAT, resulting in $\mathrm{pHN}[\mathrm{Sw}-\mathrm{X}]$. The P1 and $\mathrm{CP}$ regions were also substituted together to generate $\mathrm{pHN}[\mathrm{Sw}-\mathrm{X}+\mathrm{Sl}-\mathrm{Bs}]^{*}$. The progeny derived from these three chimeras all caused wilting, indicating that neither the $\mathrm{CP}$ nor the P1 coding regions alone or combined were enough to alter the wilting phenotype. In addition, the chimera $\mathrm{pHN}[\mathrm{Sw}-\mathrm{X}+$ Sl-Bs]* indicated that the XbaI-SalI fragment of TEV HAT contained a wilting determinant. Therefore, two more chimeras were constructed by substituting pTEV-HAT fragments into pTEV-NW in order to further locate the determinant of the wilting response. First, an EcoRI-BamHI (positions 4,264 to

A

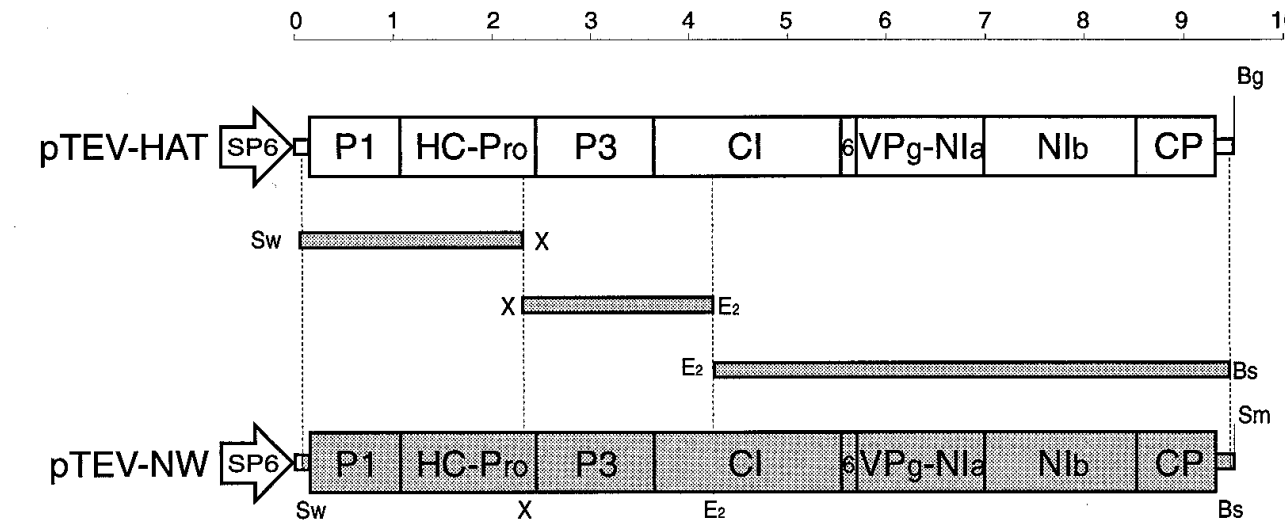

B
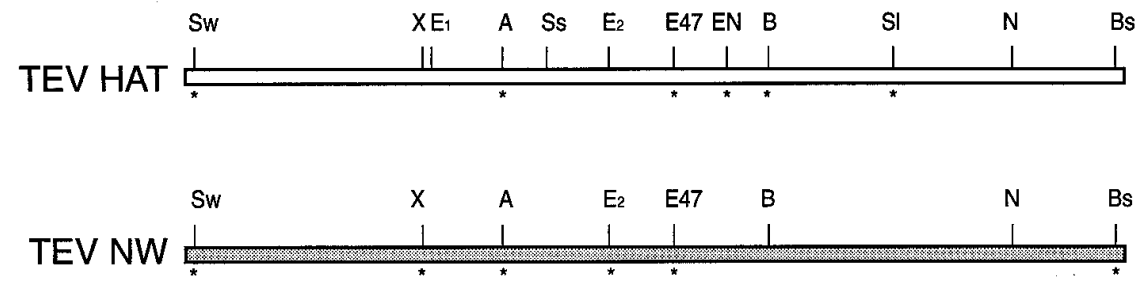

Fig. 1. Plasmids containing the viral cDNA inserts used in this study. A, Strategy for construction of pTEV-NW. Under the scale bar are the genome maps of pTEV-HAT (Dolja et al. 1992) and pTEV-NW, which contain full-length clones of the tobacco etch virus that causes wilting (TEV HAT) and the nonwilting (TEV NW) genomes, respectively, downstream from the SP6 RNA polymerase promoter (indicated by an arrow). The maps show the untranslated regions (small boxes) and the different coding regions (large boxes); TEV HAT and TEV NW sequences are represented by open and shadowed boxes, respectively. The three TEV NW cDNA fragments used for obtaining the full-length clone are represented by bars flanked by abbreviations for the restriction sites. B, Restriction endonuclease cleavage sites of TEV and TEV NW that were used to generate chimeras by substitution of fragments between clones of the two strains. Unique sites are marked with an asterisk. Sm $=S m a \mathrm{I} ; \mathrm{Sw}=S w a \mathrm{I} ; \mathrm{X}=X b a \mathrm{I} ; \mathrm{E}_{1}=E c o R \mathrm{I}$, first site; A = AatII; Ss = SstI; $\mathrm{E}_{2}=$ EcoRI, second site; E47 = Eco47III; EN = EcoNI; B = BamHI; Sl = SalI; N = NsiI; and Bs = BstEII. 
$5,916)$ chimera ( $\left.\mathrm{pNH}\left[\mathrm{E}_{2}-\mathrm{B}\right]\right)$ was tested. A further substitution within the EcoRI-BamHI region was made to create an Eco47III-BamHI chimera (pNH[E47-B]). Tests of the progeny virus derived from these two constructs showed that insertion of either the pTEV-HAT EcoRI-BamHI or Eco47III-BamHI fragment into pTEV-NW changed the nonwilting response to wilting. The Eco47III-BamHI fragment, encoding the C-terminal region of $\mathrm{CI}, 6-\mathrm{kDa}$ protein, and the $\mathrm{N}$-terminal region of $\mathrm{VPg}$, therefore, contains sufficient sequence for eliciting the wilting response.

In order to determine whether the TEV NW Eco47IIIBam HI region was able to alter the wilting response of TEV HAT, the reciprocal exchange pHN[E47-B] chimera was tested (Fig. 2). The progeny virus derived from this chimera did not alter the wilting response of TEV HAT, showing that the TEV NW Eco47III-BamHI fragment is not sufficient to alter the wilting response of Tabasco pepper caused by TEV HAT. The simplest explanation for this paradoxical result is that another, epistatic region outside the Eco47III-BamHI fragment is also able to confer the wilting phenotype.

Location of a second wilting determinant and identification of the two regions required to alter the wilting response.

To locate the other wilting determinant, several additional constructs were tested (Fig. 3). Progeny virus generated from the construct $\mathrm{pHN}\left[\mathrm{E}_{2}-\mathrm{B}\right]$ elicited wilting in Tabasco pepper, as did its reciprocal construct, $\mathrm{pNH}\left[\mathrm{E}_{2}-\mathrm{B}\right]$, shown in Figure 2. This indicates that the TEV HAT EcoRI-Eco47III $(4,264$ to 4,967) region does not contain the other wilting determinant. Progeny virus generated from the $\mathrm{pHN}[\mathrm{Sw}-\mathrm{B}]$ chimera caused mosaic symptoms and did not elicit wilt. Therefore, the SwaI-BamHI region contains all the determinants required for the wilting response. To delimit the second wilting determinant, three more chimeras were made. Progeny virus generated from the $\mathrm{pHN}\left[\mathrm{Sw}-\mathrm{X}+\mathrm{E}_{2}-\mathrm{B}\right]$ chimera elicited wilt. When the constructs $\mathrm{pHN}\left[\mathrm{Sw}-\mathrm{X}+\mathrm{E}_{2}-\mathrm{B}\right]$ and $\mathrm{pHN}[\mathrm{Sw}-\mathrm{B}]$ were compared, the only difference found between them was the EcoRI-EcoRI (2,383 to $4,264)$ region, indicating that the EcoRI-EcoRI region contains the second wilting determinant. However, the progeny of the $\mathrm{pHN}\left[\mathrm{E}_{1}-\mathrm{E}_{2}\right]$ chimera did not alter the wilting of Tabasco, indicating that the second determinant alone also is not sufficient to alter the response. The progeny of construct $\mathrm{pHN}\left[\mathrm{E}_{1}-\mathrm{B}\right]$, containing both the EcoRI-EcoRI $(2,383$ to 4,264$)$ and EcoRI-BamHI $(4,264$ to 5,916) regions from TEV NW, did not elicit wilt in Tabasco pepper, showing that this region contains all the TEV NW sequences required to alter wilting.

A search was then conducted to identify the minimal areas within this region that are responsible for altering the wilting response (Fig. 3). The progeny virus derived from the pHN[AB] construct did not wilt Tabasco, indicating that all required sequences are located within this area. The next chimeras constructed were $\mathrm{pHN}[\mathrm{Ss}-\mathrm{B}]$ and $\mathrm{pHN}[\mathrm{A}-\mathrm{EN}]$. Neither of these two constructs generated viral progeny able to alter the wilting response. Two more constructs, designed to substitute two regions of TEV NW into pTEV-HAT, were obtained: $\mathrm{pHN}\left[\mathrm{A}-\mathrm{E}_{2}+\mathrm{EN}-\mathrm{B}\right]$ and $\mathrm{pHN}[\mathrm{A}-\mathrm{Ss}+\mathrm{EN}-\mathrm{B}]$. Progeny virus derived from these two constructs did not cause wilting of

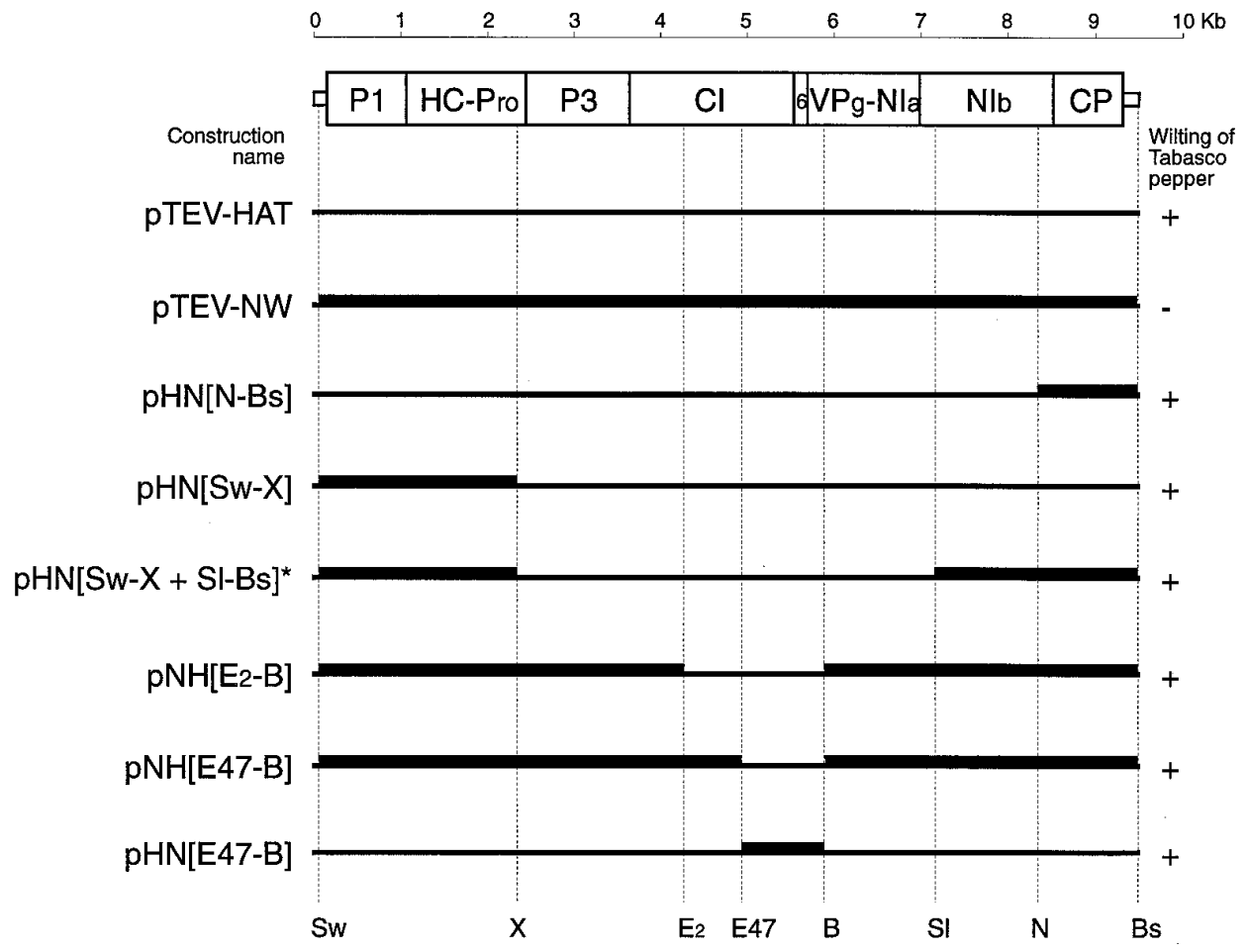

Fig. 2. Chimeras constructed from pTEV-HAT and pTEV-NW used to locate the first wilting determinant and to provide evidence of the existence of a second determinant. Under the scale bar and genome map, chimeras are represented by thin (tobacco etch virus [TEV HAT], which causes wilting) and thick (TEV NW, nonwilting) bars with their names on the left. Positions of the restriction sites (below the diagram) used for substitution of fragments are indicated by dashed vertical lines and are abbreviated as follows: $\mathrm{Sw}=$ SwaI; X $=$ XbaI; $\mathrm{E}_{2}=$ EcoRI, second site; E47 = Eco47III; B = BamHI; Sl = SalI; $\mathrm{N}=N s i \mathrm{I}$; and $\mathrm{Bs}=B s t \mathrm{EII}$. The symptoms on Tabasco pepper produced by the progeny of each clone are indicated on the right. 
Tabasco pepper, indicating that the TEV NW regions AatIISstI $(3,193$ to 3,600$)$ and EcoNI-BamHI $(5,463$ to 5,916), spanning 407 and 453 base pairs, respectively, are both required to alter the wilting response of TEV HAT. Substitution of either one of these fragments alone, such as in pHN[A-Ss] or $\mathrm{pHN}[\mathrm{EN}-\mathrm{B}]$, was not sufficient to alter wilting. These determinants are located in the coding regions of the $\mathrm{P} 3$, the $\mathrm{CI}$, and the 6-kDa and VPg-NIa proteins.

\section{Amino acid sequence alignment of the AatII-SstI} and EcoNI-BamHI regions of TEV NW and TEV HAT.

The derived amino acid sequences within the regions of
TEV NW and TEV HAT shown to affect the wilt response were aligned and compared (Fig. 4). Within the AatII-SstI $(3,193$ to 3,600) region, there are seven amino acid changes in the P3 protein, some of them, such as Asn to Lys (N1065K) and Glu to Ala (E1120A), involving dramatic alterations of charge or polarity. Within the EcoNI-BamHI $(5,463$ to 5,916$)$ region there is one change $(\mathrm{G} 1782 \mathrm{~S})$ in the $\mathrm{C}$-terminal portion of $\mathrm{CI}$, two in the $6-\mathrm{kDa}$ protein, and one conservative predicted amino acid change $(\mathrm{K} 1855 \mathrm{R})$ in the $\mathrm{N}$-terminal region of the VPg-NIa. The minimal number of amino acid changes required for altering the wilting response remains to be determined.

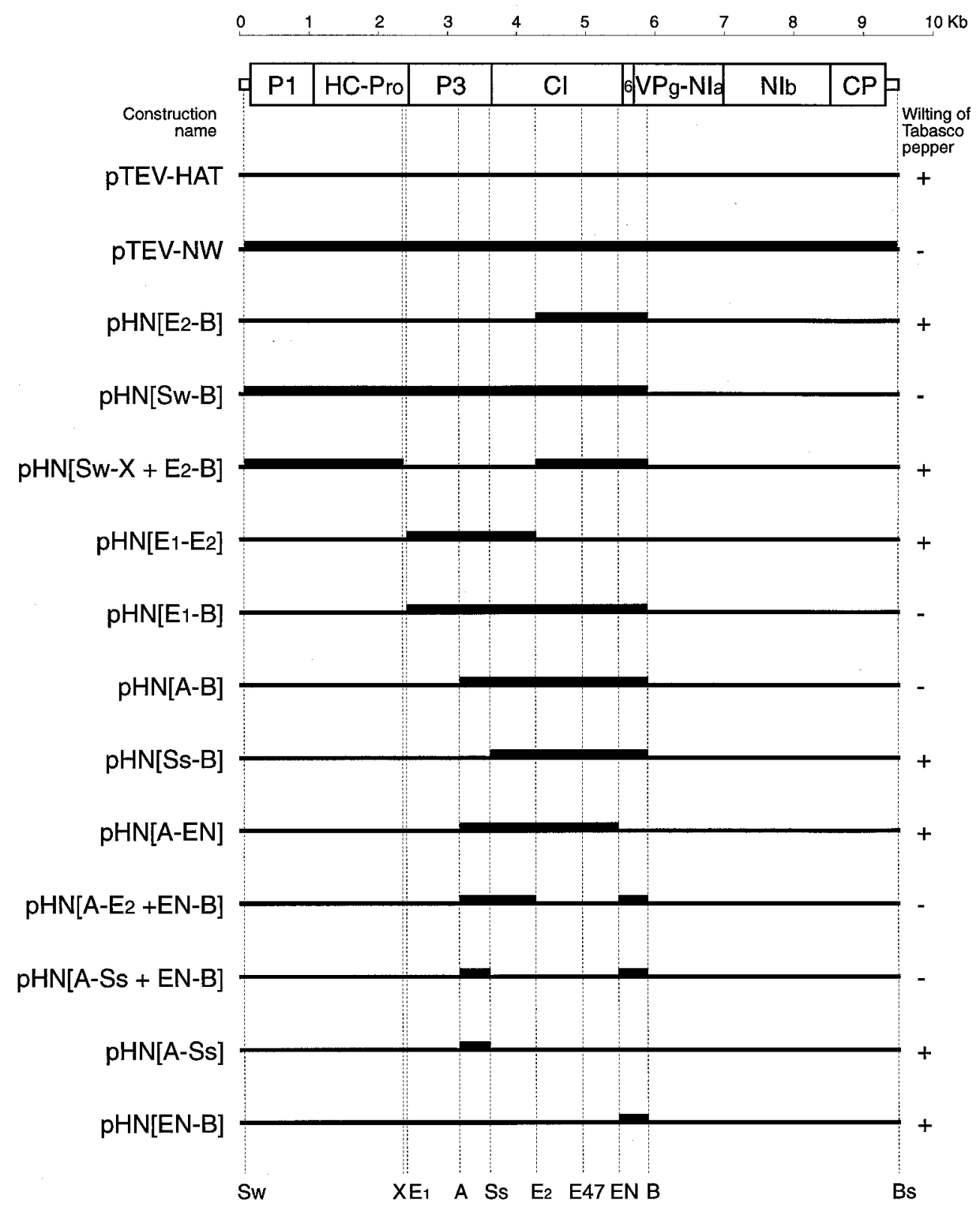

Fig. 3. Chimeras constructed from pTEV-HAT and pTEV-NW used to locate the second wilting determinant and to identify the two regions required for the nonwilting response. Under the scale bar and genome map, chimeras are represented by thin (tobacco etch virus [TEV HAT], which causes wilting) and thick (TEV NW, nonwilting) bars with their names indicated on the left. Positions of the restriction sites (below the diagram) used for substitution of fragments are indicated by dashed vertical lines and are abbreviated as follows: $\mathrm{Sw}=$ SwaI; $\mathrm{X}=\mathrm{Xba \textrm {I }}$; $\mathrm{E}_{1}=$ EcoRI, first site; $\mathrm{A}=A a t \mathrm{II} ; \mathrm{Ss}=$ SstI; $\mathrm{E}_{2}=$ EcoRI, second site; E47 = Eco47III; EN = EcoNI; B = BamHI; and Bs = BstEII. The symptoms on Tabasco pepper produced by the progeny of each clone are indicated on the right. 


\section{In vitro transcription and translation}

and analysis of the proteolytic products.

Since several proteolytic processing sites (P3/putative 6$\mathrm{kDa}, \mathrm{CI} / 6-\mathrm{kDa}$, and 6-kDa/VPg-NIa) reside in the delimited areas, we investigated whether the regulation of processing is involved in the wilting phenotype by analyzing in vitro transcription-translation products. One of the amino acid changes in the first region, the mutation of Val to Ile (V1108I), is present within the heptapeptide (Dougherty and Parks 1989) defining the putative NIa-mediated cleavage site reported in plum pox potyvirus (PPV) to generate a $6-\mathrm{kDa}$ protein at the C-terminal region of P3 (Garcia et al. 1992).

The constructs pTEV-HAT $\Delta \mathrm{Sw}-\mathrm{H} / \mathrm{Sl}$ and $\mathrm{pHN}[\mathrm{A}-\mathrm{B}] \Delta \mathrm{Sw}-$ $\mathrm{H} / \mathrm{Sl}$, from TEV HAT and TEV NW, respectively, encode a truncated form of the TEV polyprotein including the C-terminal two-thirds of P3; all of CI, 6-kDa, and VPg-NIa; and the first two-thirds of NIb. An electrophoretic analysis of the proteolytic products generated over time after in vitro transcrip-

TEV HAT

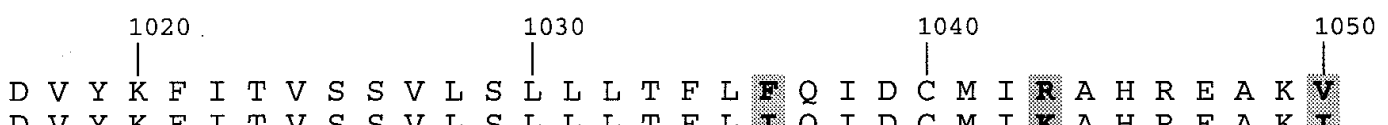

TEV NW D V Y

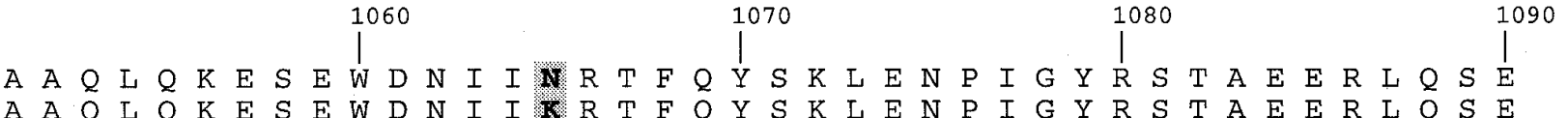

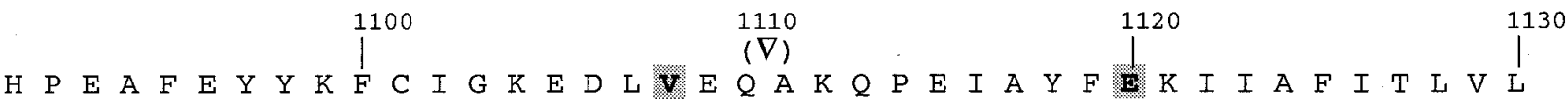
H P E A F E Y Y K F C I GK E D L I E Q A K Q P E I A Y F A K I I A F I T L V L

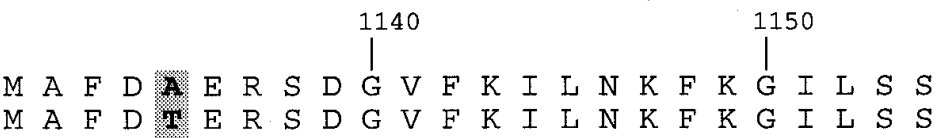

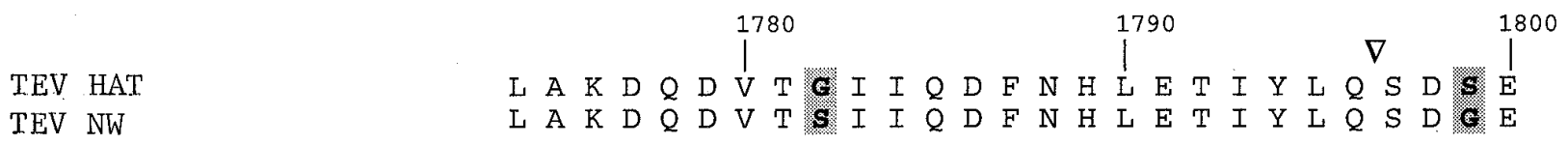

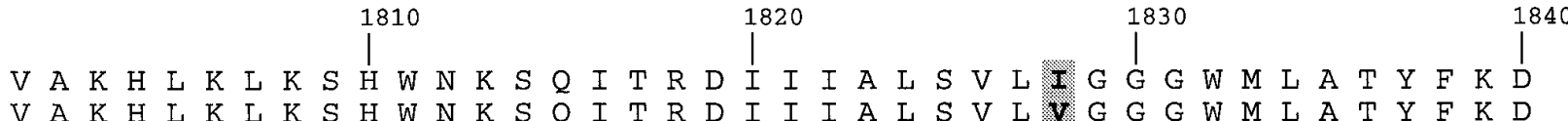

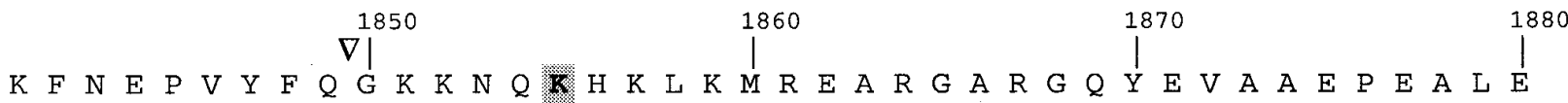

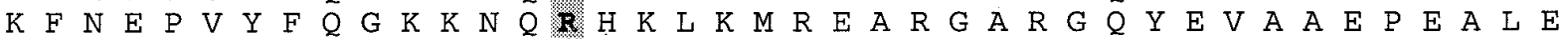

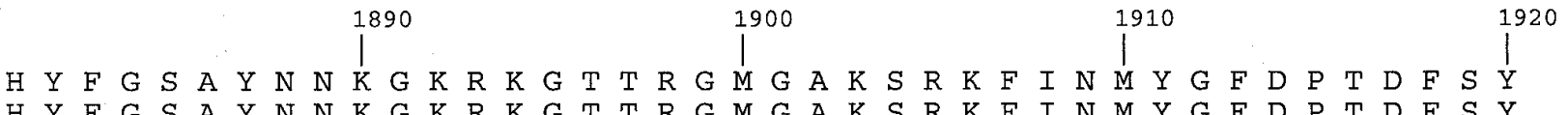

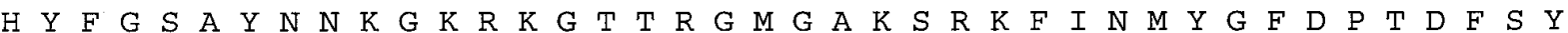

$\begin{array}{lllllllll}I & R & F & V & D\end{array}$

I R F V D

Fig. 4. Amino acid sequence alignment of the two regions involved in altering the wilting response. Sequences of tobacco etch virus (TEV HAT) (above), which causes wilting, and TEV NW (nonwilting) (below) in the C-terminal region of P3 (top figure) and the C-terminal region of CI, the 6-kDa, and the N-terminal region of VPg-NIa (bottom figure) are compared. Bold letters in shadowed boxes indicate differences between proteins, and cleavage sites are indicated with arrowheads. Underlined residues show the hydrophobic domains present in the 6-kDa protein (Restrepo-Hartwig and Carrington, 1994) or in the putative 6-kDa product located at the C terminus of P3 (Riechmann et al., 1995), with its proposed cleavage site indicated by an arrowhead in parentheses. 
tion-translation of these two constructs did not show noticeable differences in size of products or in the relative cleavage rates during the incubation period (not shown). At least five different products, of approximately $31 \mathrm{kDa}, 49 \mathrm{kDa}, 71 \mathrm{kDa}$, $100 \mathrm{kDa}$, and $150 \mathrm{kDa}$, were observed. The higher $(\sim 150-$ $\mathrm{kDa}$ ) product appeared after $30 \mathrm{~min}$ of incubation, along with the rest of products generated, presumably by action of the NIa protease on the viral substrate. No apparent processing of the P3-related 31-kDa product into $25+6-\mathrm{kDa}$ was observed, confirming previous observations (Parks et al. 1992) that in TEV no processing of the cleavage site described for PPV (Garcia et al. 1992) occurs in a cell-free system.

\section{DISCUSSION}

We have defined viral sequences involved in the wilting response of Tabasco pepper to TEV by construction of chimeras between TEV HAT and the nonwilting strain, TEV NW. Two separate regions in TEV NW contain genetic determinants necessary to alter the wilting response of Tabasco pepper to infection with TEV HAT. We have shown that TEV HAT possesses two wilting determinants and that replacement of only one of them with its counterpart from TEV NW does not alter the wilt phenotype.

In other necrosis-inducing virus-plant interactions, a single or a few amino acid substitutions in specific viral gene products were sufficient to alter the interaction between virus and host. For instance, resistance genes can be overcome by a single amino acid substitution in the CP gene of TMV in Nicotiana sylvestris carrying the $N^{\prime}$ gene (Knorr and Dawson 1988) or in the CP of PVX in potato (Santa Cruz and Baulcombe 1993). In tomato mosaic virus, two concomitant base substitutions in the $126-\mathrm{kDa}$ protein overcome the effects of the Tm-1 resistance gene in tomato (Meshi et al. 1988), and different amino acid substitutions in the movement protein confer the ability to overcome $T m-2$ and $T m-2^{2}$ resistance genes in tomato (Meshi et al. 1989; Weber et al. 1993). A single mutation in the $126-\mathrm{kDa}$ gene of the same virus is responsible for overcoming $N$ gene-mediated resistance in tobacco (Padgett and Beachy 1993). Alterations that affect the stability of the quaternary structure of TMV CP also lead to the hypersensitive response (Culver et al. 1991; Culver et al. 1994). These examples show that usually a single viral gene product triggers the hypersensitive response when recognized by the host plants, and therefore changes affecting this particular gene product are found in strains that overcome the resistance mechanism. In contrast, in our system the two determinants mapped to separate regions in the TEV genome. It can be speculated that the different genes involved need to act together to perform the functions required to overcome the wilting response.

The first physiological change detectable in the roots of TEV-infected Tabasco plants, 1 to 2 days before wilt symptoms occur, is a release of electrolytes, indicative of permeability change (Ghabrial and Pirone 1967). The dramatic loss of ions suggests damage to membranes, which might be caused by response to specific viral factors. The identification of the viral gene products that may be involved in the wilting response is difficult because of the number of possibilities. However, several of the gene products within the delimited regions are known to be membrane associated. The first region is located within the $\mathrm{C}$-terminal portion of the $\mathrm{P} 3$ protein, while the second region includes the $\mathrm{C}$ terminus of the $\mathrm{CI}$, the 6-kDa polypeptide, and part of the VPg-NIa coding regions. The 6-kDa protein has been shown to be membrane-associated with a conserved central hydrophobic domain flanked by hydrophilic residues suggested to function as an anchor by insertion into the lipid bilayer (Restrepo-Hartwig and Carrington 1994). Interestingly, a similar structure is present in the putative 6-kDa protein, which can be produced by NIa-mediated processing at the $\mathrm{C}$ terminus of $\mathrm{P} 3$ in PPV (Garcia et al. 1992; Riechmann et al. 1995). The two mutations, E1120A and A1135T, found in this region of TEV NW are located in or adjacent to the conserved hydrophilic positions flanking the hydrophobic domain. However, in TEV, this processing has not been observed in vitro (Parks et al. 1992), and the processing in vivo at this junction has been shown not to be required for virus viability, although it has an effect on symptom expression of PPV (Riechmann et al. 1995). The mutation V1108I in TEV NW affects the heptapeptide defining this possible cleavage site, and this theoretically could modify the regulation of processing. We attempted to check this by analysis of in vitro transcription-translation products but did not find evidence for such processing. Our results did not show differences between the constructs derived from pTEV-HAT and a chimera with the nonwilting phenotype, although the possibility of a different behavior in vivo cannot be excluded. Additionally, Riechmann et al. (1995) suggested that in vivo processing could be a way to regulate the activity of the P3 protein and that TEV may have evolved to make this level of control dispensable. It has been suggested that the P3 protein is involved in the replication of the potyviral RNA and is associated with the CI (Rodriguez-Cerezo et al. 1993; Klein et al. 1994), but its specific function or functions remain unknown.

Several viral functions are associated with the protein products included in the second region. The functions of the potyviral CI protein, including RNA binding and NTPase and helicase activities, have been demonstrated in vitro (Fernandez et al. 1995; Lain et al. 1990). The helicase domain of the potyviral CI protein is in the $\mathrm{N}$-terminal half of the molecule. The C-terminal half, which is less conserved among different potyviruses, shows no homology with other known proteins (Lain et al. 1989), and it is in this area that the change G1782S is located in TEV NW. Other functions suggested for the CI include attachment of the replication complex to membranes (Domier et al. 1987) and virus transport from cell to cell (Langenberg 1986). The proteolytic cleavage between CI and 6-kDa is not optimal; therefore, $\mathrm{CI}-6-\mathrm{kDa}$ may exist in vivo as a precursor (Restrepo-Hartwig and Carrington 1992). It was also found that autoproteolysis between the 6-kDa protein and NIa is necessary for transportation into nuclei (Restrepo-Hartwig and Carrington 1992). The 6-kDa protein itself is thought to function in the replication process by anchoring the CI and/or the VPg-NIa proteins on membranes through its stretch of hydrophobic amino acids (Restrepo-Hartwig and Carrington 1994; Riechmann et al. 1992). Only two amino acid changes, S1799G and V1828I, affected the 6-kDa region in TEV NW. The last amino acid mutation in this region, $\mathrm{R} 1855 \mathrm{~K}$, is a conservative change located near the $\mathrm{N}$ terminus of the VPg-NIa product, but it affects neither the nuclear localization signal nor the position of the viral RNA attach- 
ment site (Schaad et al. 1996). Further experimentation is needed to identify the viral functions that are involved in the wilting response as well as the mechanisms involved in the plant response to infection. Although we have focused here on the predicted amino acid differences between TEV HAT and TEV NW, the idea that differences at the nucleotide level might play a role in the wilting response cannot be excluded.

The wilting response caused by necrosis of cells in the vascular system of the roots (White and Horn 1965) has been considered diagnostic for TEV (Purcifull and Hiebert 1982). This rapid response limits virus spread, because wilted plants are poor sources of virus for vectors. It could be argued that the selection pressure against this effect of TEV on Tabasco pepper should be so high that it would soon have resulted in selection of strains such as TEV NW. However, to this date, TEV NW is the only TEV isolate shown not to wilt Tabasco pepper. The resilient nature of wilt-causing TEV isolates may relate to the essentiality of the genes involved for other functions and, as shown in this study, the number of determinants required for altering the wilting phenotype.

\section{MATERIALS AND METHODS}

\section{Construction of pTEV-NW.}

Standard molecular biology techniques were employed throughout these studies (Sambrook et al. 1989). TEV NW cDNA synthesis, cloning, and nucleotide sequence analysis were previously described (Chu et al. 1995). A full-length cDNA clone of TEV NW (pTEV-NW) was constructed in three steps: first, a TEV NW SwaI-XbaI (78 to 2,329) cDNA fragment was inserted into the corresponding positions in pTEV-HAT, and the BglII site downstream from the poly(A) tail was replaced by $S m a I$ (this was necessary because of the presence of another $B g l I I$ site in the TEV NW sequence at position 8,236); second, a TEV NW XbaI-EcoRI (2,329 to $4,264)$ cDNA fragment was substituted into the first chimera; and third, the remaining TEV NW EcoRI-BstEII (4,264 to $9,461)$ cDNA fragment was inserted to complete pTEV-NW (Fig. 1A).

\section{Construction of chimeric plasmids.}

The localization of a wilting determinant was pursued by exchanging fragments between pTEV-NW and pTEV-HAT. In spite of the fact that the difference in nucleotide sequence identity between TEV HAT and TEV NW is only $8 \%$ (Chu et al. 1995), some significant differences in the restriction maps precluded direct exchange of certain fragments between the two full-length clones (Fig. 1B). Nucleotide sequence mutations were introduced in some cases to create compatible restriction sites between the two cDNAs. Several mutations were incorporated into the cDNAs by reverse transcriptase polymerase chain reaction (RT-PCR) on viral RNAs, and others were created by PCR mutagenesis of previously constructed clones with relevant mutagenic primers (Atreya et al. 1992). None of these changes resulted in amino acid alteration. The RT-PCR or PCR products were digested with restriction enzymes for cloning, and the recombinant clones were screened by restriction enzyme digestion and/or sequencing when required. In several cases, intermediate cloning steps were necessary in order to permit interchange of fragments not flanked by unique sites. Plasmids pBluescript II SK(-)
(Stratagene, La Jolla, CA) and pSP65 (Promega, Madison, WI) were used for subcloning, and some of the initially obtained chimeric constructs were used as starting points to facilitate construction of derivatives.

The selected restriction sites (Fig. 1B) used to substitute fragments between pTEV-HAT and pTEV-NW, with the abbreviations used and their positions in parentheses, were SwaI (Sw, position 78, unique in both sequences); XbaI (X, 2,329); EcoRI, first site ( $\mathrm{E}_{1}, 2,383$, not present at this position in the TEV NW sequence); AatII (A, 3,193, unique in both sequences); Sst I (Ss, 3,600, not present at this position in the TEV HAT sequence); EcoRI, second site (E $\left.\mathrm{E}_{2}, 4,264\right)$; Eco47III (E47, 4,967, unique in both sequences); EcoNI (EN, 5,463, not present in the TEV NW sequence), $\operatorname{BamHI}(\mathrm{B}, 5,916)$; SalI (Sl, 7,166, not present in this position in the TEV NW sequence); $N$ siI (N, 8,333); and BstEII (Bs, 9,461).

The chimeras in Figures 2 and 3 and others used as intermediate cloning steps were made as follows:

pHN[N-Bs]. A BglII linker sequence was first inserted into the pBluescript II SK(-) phagemid at the SmaI site, and the pTEV-HAT SalI-BglII (from position 7,166 to after the poly(A) tail) fragment was then cloned into the plasmid. The unique NsiI site in the resulting construct was utilized to insert the TEV NW Nsi-BstEII $(8,333$ to 9,461) region, which covers the entire CP coding region, into the construct and finally into pTEV-HAT.

pHN[Sw-X]. The TEV NW SwaI-XbaI (78 to 2,329) fragment was inserted into pTEV-HAT.

$\mathrm{pHN}[\mathrm{Sw}-\mathrm{X}+\mathrm{Sl}-\mathrm{Bs}]^{*}$. Because of the presence of a $B g l \mathrm{II}$ site at position 8,236 of the TEV NW cDNA, it was necessary to replace the $B g l$ III site downstream from the poly(A) tail of the $\mathrm{pHN}[\mathrm{Sw}-\mathrm{X}]$ chimera with a SmaI site, resulting in $\mathrm{pHN}[\mathrm{Sw}-\mathrm{X}]^{*}$. A silent mutation was then introduced at the SalI site to facilitate making a SalI-BstEII $(7,166$ to 9,461$)$ fragment by RT-PCR of the TEV NW RNA, allowing insertion of the corresponding fragment.

$\mathrm{pNH}\left[\mathrm{E}_{2}-\mathrm{B}\right]$. Because of the presence of a second BamHI site (at position 5,096) within the TEV NW EcoRI-BamHI $(4,264$ to 5,916$)$ region, a pTEV-HAT EcoRI-BamHI $(4,264$ to $5,916)$ fragment was inserted into that of pTEV-NW.

pNH[E47-B]. A further substitution within the EcoRIBamHI $(4,264$ to 5,916$)$ region was made by inserting the pTEV-HAT Eco47III-BamHI $(4,967$ to 5,916) fragment into pTEV-NW.

$\mathrm{pHN}[\mathrm{E} 47-\mathrm{B}]$ and $\mathrm{pHN}[\mathrm{EN}-\mathrm{B}]$. Oligonucleotides were designed to introduce an EcoNI site into TEV NW, without alteration of an amino acid, at position 5,463. The TEV NW Eco47III-EcoNI (4,967 to 5,463) and EcoNI-BamHI (5,463 to $5,916)$ fragments, respectively, were inserted into pTEV-HAT.

$\mathrm{pHN}\left[\mathrm{E}_{2}-\mathrm{B}\right]$. The construct $\mathrm{pHN}[\mathrm{E} 47-\mathrm{B}]$ was digested with EcoRI and Eco47III, resulting in loss of the EcoRI-EcoRI $(2,383$ to 4,264$)$ fragment, which was reinserted after insertion of the EcoRI-Eco47III fragment from pTEV-HAT.

$\mathrm{pHN}\left[\mathrm{E}_{1}-\mathrm{E}_{2}\right]$ and $\mathrm{pHN}\left[\mathrm{E}_{1}-\mathrm{B}\right]$. A new EcoRI site was created by PCR amplification at position 2,383, and the EcoRI-EcoRI $(2,383$ to 4,264$)$ fragment of TEV NW was then inserted into pTEV-HAT or $\mathrm{pHN}\left[\mathrm{E}_{2}-\mathrm{B}\right]$.

$\mathrm{pHN}\left[\mathrm{Sw}-\mathrm{X}+\mathrm{E}_{2}-\mathrm{B}\right]$. The TEV NW SwaI-XbaI (78 to 2,329) region was inserted into $\mathrm{pHN}\left[\mathrm{E}_{2}-\mathrm{B}\right]$.

pHN[Sw-B]. The TEV NW SwaI-EcoRI (78 to 4,264) region was inserted into $\mathrm{pHN}\left[\mathrm{E}_{2}-\mathrm{B}\right]$. 
pHN[A-B]. The AatII-AatII fragment, from an AatII site present in the vector upstream of the SP6 promoter to position 3,193 , was inserted into $\mathrm{pHN}\left[\mathrm{E}_{1}-\mathrm{B}\right]$ and screened for the proper orientation.

pHN[Ss-B]. PCR-mediated mutagenesis was used to create a $S s t$ I site at position 3,600 in pTEV-NW. An intermediate chimeric subclone was constructed in pSP65 containing the EcoRI-SstI $(2,382$ to 3,600) fragment of pTEV-HAT and from this new site to BamHI $(5,916)$ of pTEV-NW. The EcoRIEcoRI $(2,382$ to 4,264) fragment of this intermediate construct was then inserted in the correct orientation into $\mathrm{pHN}[\mathrm{A}-\mathrm{B}]$.

pHN[A-EN]. The fragment Eco47III-BglII (4,967 to downstream of the poly(A) tail) from the intermediate construct $\mathrm{pHN}[\mathrm{E} 47-\mathrm{EN}]$ was inserted into $\mathrm{pHN}[\mathrm{A}-\mathrm{B}]$.

pHN[A-E ${ }_{2}+$ EN-B]. The EcoRI-EcoRI $(2,382$ to 4,264) fragment of $\mathrm{pHN}[\mathrm{A}-\mathrm{B}]$ was substituted into $\mathrm{pHN}[\mathrm{EN}-\mathrm{B}]$.

pHN[A-Ss + EN-B] and pHN[A-Ss]. A chimeric subclone derived from $\mathrm{pHN}[\mathrm{A}-\mathrm{B}]$ created through PCR mutagenesis contained the fragment from EcoRI $(2,382)$ to a new SstI site at position 3,600. The SstI-BamHI $(3,600$ to 5,916) region from pTEV-HAT was then inserted, and the corresponding EcoRI-EcoRI $(2,382$ to 4,264$)$ fragment was substituted into pHN[EN-B] or pTEV-HAT.

\section{In vitro transcription and inoculation of plants with RNA transcripts.}

The pTEV-HAT, pTEV-NW, and $\mathrm{pHN}$ or $\mathrm{pNH}$ chimeric constructs resulting from the substitution experiments were linearized with $B g l \mathrm{II}$ or, in some cases with $S m a \mathrm{I}$, and used for in vitro transcription with SP6 RNA polymerase (GIBCO BRL, Grand Island, NY) in the presence of $\mathrm{m}^{7} \mathrm{GpppG}$ cap analog (New England Biolabs, Beverly, MA). Tobacco seedlings (cultivar Kentucky 14) were directly inoculated with the capped transcripts, and sap from infected tobacco plants was then used for inoculation of Tabasco pepper (seedlings 4 to 5 in. tall). The symptoms, i.e., wilting or mosaic with no wilting, developed on Tabasco pepper 5 to 7 days after inoculation.

\section{Confirmation of the constructs and progeny viral sequences.}

The nature of each of the chimeras constructed was confirmed by restriction mapping or DNA sequencing before in vitro transcriptions were done. Their presence in inoculated tobacco plants was confirmed by RT-PCR amplification of the viral RNAs extracted from infected tobacco plants (Atreya et al. 1991) followed by direct sequencing of the PCR product with Vent $_{\mathrm{R}}\left(\mathrm{exo}^{-}\right)$DNA polymerase (New England Biolabs) and/or digestion with specific restriction enzymes that differentiated the sequences of TEV NW and TEV HAT cDNAs.

\section{In vitro transcription and translation for proteolytic processing analysis.}

Two full-length plasmids, pTEV-HAT and chimeric pHN[A-B] (containing the AatII-BamHI fragment from TEV $\mathrm{NW}$ ), were used to engineer the constructs used in transcription, translation, and proteolytic processing analysis experiments. In both plasmids, digestion with $S w a I$ (position 78) and HpaI (abbreviated as $\mathrm{H}$, position 2,679) followed by ligation produced a deletion from within the $5^{\prime}$ untranslated sequence to the $5^{\prime}$ portion of the $\mathrm{P} 3$ coding region, resulting in $\mathrm{pTEV}$ -
HAT $\Delta \mathrm{Sw}-\mathrm{H}$ and $\mathrm{pHN}[\mathrm{A}-\mathrm{B}] \Delta \mathrm{Sw}-\mathrm{H}$. Linearization with SalI (position 7,165) generated templates able to produce a truncated form of the polyprotein after in vitro transcription-translation, including the C-terminal two-thirds of P3 (from the first in-frame AUG codon located at position 2,794), CI, 6$\mathrm{kDa}, \mathrm{VPg}-\mathrm{NIa}$, and the first 180 amino acids of NIb.

Transcription of pTEV-HAT $\Delta \mathrm{Sw}-\mathrm{H} / \mathrm{Sl}$ - and $\mathrm{pHN}$ [A-B] $\Delta \mathrm{Sw}-\mathrm{H} / \mathrm{Sl}$-linearized plasmids was performed with SP6 RNA polymerase essentially as described before but without inclusion of the cap analog. The RNA products were precipitated with $2 \mathrm{M} \mathrm{LiCl}$ and resuspended in sterile water. Equal amounts of RNA (approximately $5 \mu \mathrm{g}$ ) were then translated with a Wheat Germ Extract system (Promega) in the presence of $\left[{ }^{35} \mathrm{~S}\right]$ methionine, and aliquots were removed from the reaction mixture at different time points of incubation up to $2 \frac{1}{2} \mathrm{~h}$. The translation reaction, and the processing of products by the endogenous NIa $(49-\mathrm{kDa})$ protease, was stopped by adding sample buffer and heating at $100^{\circ} \mathrm{C}$ for $10 \mathrm{~min}$. Samples were electrophoresed in sodium dodecyl sulfate-polyacrylamide gel electrophoresis 4 to $20 \%$ gradient gels (Bio-Rad, Hercules, $\mathrm{CA})$ for detection of the processing products.

\section{ACKNOWLEDGMENTS}

The authors thank A. Metcalf and J. Baker for technical assistance and J. G. Shaw and S. A. Ghabrial for critical reading. J. J. Lopez-Moya and C. Llave-Correas were recipients of fellowships from the Ministerio de Educación y Ciencia (Spain). Financial support was provided by the U.S.-Israel Binational Agricultural Research and Development Fund (BARD).

\section{LITERATURE CITED}

Allison, R., Johnston, R. E., and Dougherty, W. G. 1986. The nucleotide sequence of the coding region of tobacco etch virus genomic RNA: Evidence for the synthesis of a single polyprotein. Virology 154:9-20.

Atreya, P. L., Atreya, C. D., and Pirone, T. P. 1991. Amino acid substitutions in the coat protein result in loss of insect transmissibility of a plant virus. Proc. Natl. Acad. Sci. USA 88:7887-7891.

Atreya, C. D., Atreya, P. L., and Pirone, T. P. 1992. Construction of inframe chimeric plant viral genes by simplified PCR strategies. Plant Mol. Biol. 19:517-522.

Brakke, M. K. 1970. Systemic infections for the assay of plant viruses. Annu. Rev. Phytopathol. 8:61-84.

Chu, M. H., Johnson, M., Thornbury, D. W., Black, L., and Pirone, T. P. 1995. Nucleotide sequence of a strain of tobacco etch virus that does not cause Tabasco pepper wilt. Virus Genes 10:283-288.

Culver, J. N., Lindbeck, A. G. C., and Dawson, W. O. 1991. Virus-host interactions: Induction of chlorotic and necrotic responses in plants by tobamoviruses. Annu. Rev. Phytopathol. 29:193-217.

Culver, J. N., Stubbs, G., and Dawson, W. O. 1994. Structure-function relationship between tobacco mosaic virus coat protein and hypersensitivity in Nicotiana sylvestris. J. Mol. Biol. 242:130-138.

Dolja, V. V., McBride, H. J., and Carrington, J. C. 1992. Tagging of plant potyvirus replication and movement by insertion of $\beta$-glucuronidase into the viral polyprotein. Proc. Natl. Acad. Sci. USA 89:1020810212.

Domier, L. L., Shaw, J. G., and Rhoads, R. E. 1987. Potyviral proteins share amino acid sequence homology with picorna-, como-, and caulimoviral proteins. Virology 158:20-27.

Dougherty, W. G., and Parks, T. D. 1989. Molecular genetic and biochemical evidence for the involvement of the heptapeptide cleavage sequence in determining the reaction profile at two tobacco etch virus cleavage sites in cell-free assays. Virology 172:145-155.

Fernandez, A., Lain, S., and Garcia, J. A. 1995. RNA helicase activity of the plum pox potyvirus CI protein expressed in Escherichia coli. Mapping of an RNA binding domain. Nucleic Acids Res. 23:13271332 . 
Garcia, J. A., Martin, M. T., Cervera, M. T., and Riechmann, J. L. 1992. Proteolytic processing of the plum pox virus polyprotein by the NIa protease at a novel cleavage site. Virology 188:697-703.

Ghabrial, S. A., and Pirone, T. P. 1967. Physiology of tobacco etch virusinduced wilt of Tabasco peppers. Virology 31:154-162.

Klein, P. G., Klein, R. R., Rodriguez-Cerezo, E., Hunt, A. G., and Shaw. J. G. 1994. Mutational analysis of the tobacco vein mottling virus genome. Virology 204:759-769.

Knorr, D. A., and Dawson, W. O. 1988. A point mutation in the tobacco mosaic capsid protein gene induces hypersensitivity in Nicotiana sylvestris. Proc. Natl. Acad. Sci. USA 85:170-174.

Lain, S., Riechmann, J. L., Martin, M. T., and Garcia, J. A. 1989. Homologous potyvirus and flavivirus proteins belonging to a superfamily of helicase-like proteins. Gene 82:357-362.

Lain, S., Riechmann, J. L., and Garcia, J. A. 1990. RNA helicase: A novel activity associated with a protein encoded by a positive strand RNA virus. Nucleic Acids Res. 18:7003-7006.

Langenberg, W. G. 1986. Virus protein associated with cylindrical inclusions of two viruses that infect wheat. J. Gen. Virol. 67:1161-1168.

Meshi, T., Motoyoshi, F., Adachi, A., Watanabe, Y., Takamatsu, N., and Okada, Y. 1988. Two concomitant base substitutions in the putative replicase genes of tobacco mosaic virus confer the ability to overcome the effects of a tomato resistance gene, Tm-1. EMBO J. 7:1575-1581.

Meshi, T., Motoyoshi, F., Maeda, T., Yoshiwoka, S., Watanabe, H., and Okada, Y. 1989. Mutations in the tobacco mosaic virus $30-\mathrm{kD}$ protein gene overcome Tm-2 resistance in tomato. Plant Cell 1:515-522.

Padgett, H. S., and Beachy, R. N. 1993. Analysis of a tobacco mosaic virus strain capable of overcoming $\mathrm{N}$ gene-mediated resistance. Plant Cell 5:577-586.

Parks, T. D., Smith, H. A., and Dougherty, W. G. 1992. Cleavage profiles of tobacco etch virus (TEV)-derived substrates mediated by precursor and processed forms of the TEV proteinase. J. Gen. Virol. 73: 149-155.

Purcifull, D. E., and Hiebert, E. 1982. Tobacco etch virus. No. 258 in: Descriptions of Plant Viruses. Commonw. Mycol. Inst./Assoc. Appl.
Biol., Kew, England.

Restrepo-Hartwig, M. A., and Carrington, J. C. 1992. Regulation of nuclear transport of a plant potyvirus protein by autoproteolysis. J. Virol. 66:5662-5666.

Restrepo-Hartwig, M. A., and Carrington, J. C. 1994. The tobacco etch potyvirus 6-kilodalton protein is membrane associated and involved in viral replication. J. Virol. 68:2388-2397.

Riechmann, J. L., Lain, S., and Garcia, J. A. 1992. Highlights and prospects of potyvirus molecular biology. J. Gen. Virol. 73:1-16.

Riechmann, J. L., Cervera, M. T., and Garcia, J. A. 1995. Processing of the plum pox virus polyprotein at the $\mathrm{P} 3-6 \mathrm{~K} 1$ junction is not required for virus viability. J. Gen. Virol. 76:951-956.

Rodriguez-Cerezo, E., Ammar, E. D., Pirone, T. P., and Shaw, J. G. 1993. Association of the non-structural P3 viral protein with cylindrical inclusions in potyvirus-infected cells. J. Gen. Virol. 74:19451949.

Sambrook, J., Fritsch, E. F., and Maniatis, T. A. 1989. Molecular Cloning: A Laboratory Manual. 2nd ed. Cold Spring Harbor Laboratory, Cold Spring Harbor, NY.

Santa Cruz, S., and Baulcombe, D. C. 1993. Molecular analysis of potato virus $\mathrm{X}$ isolates in relation to the potato hypersensitivity gene Nx. Mol. Plant-Microbe Interact. 6:707-714.

Schaad, M. C., Haldeman-Cahill, R., Cronin, S., and Carrington, J. C 1996. Analysis of the VPg-proteinase (NIa) encoded by tobacco etch potyvirus: Effects of mutations on subcellular transport, proteolytic processing, and genome amplification. J. Virol. 70:7039-7048.

Wang, R. Y., Gergerich, R. C., and Kim, K. S. 1994. Entry of ingested plant viruses into the hemocoel of the beetle vector Diabrotica undecimpunctata howardi. Phytopathology 84:147-153.

Weber, H., Schultze, S., and Pfitzner, A. J. P. 1993. Two amino acid substitutions in the tomato mosaic virus 30-kilodalton movement protein confer the ability to overcome the $\mathrm{Tm}-2^{2}$ resistance gene in the tomato. J. Virol. 67:6432-6438.

White, J. C., and Horn, N. L. 1965. The histology of Tabasco peppers infected with tobacco etch virus. Phytopathology 55:267-269. 